\title{
On the reduction of nuclear weapons
}

The United States, in 1946, proposed that an international authority be formed to control the dangerous parts of atomic energy. The proposal met with very little success, except to lead to the conclusion that there was no apparent reason why it was not technically feasible. Discussions on nuclear weapons testing, initiated in 1958 , reached some agreement on test restrictions in subsequent years.

The intervening years have been notable for the development both by the United States and the Soviet Union (and later by other nations) of thermonuclear weapons with yields up to 1,000 times larger than those of the weapons used at Hiroshima and Nagasaki. More recently, in the SALT I discussions, weapons control was considered; and in SALT II, some measure of understanding on strategic launch vehicles limitations was reached, resulting in the as yet unratified SALT II treaty.

The international stockpile of nuclear weapons of various degrees of lethality and yield is now commonly referred to as 50,000 nuclear weapons. Considering the casualties and damage at Hiroshima and Nagasaki caused by two relatively low-yicld fission weapons, the effects which would result from these weapons is beyond imagination. No satisfactory defense against nuclear weapons has been found. An attack on weapons in fixed silos or submarines in port can be made with accuracy, but it seems certain that a nuclear attack would be followed by a vigorous and devastating nuclear response by either the United States or the Soviet Union, because of the redundancy of their relatively survivable strategic systems.

The recent attack on an Iraqi nuclear reactor makes it clear that potential nuclear capability by an avowed enemy has led-and can again lead-to a preemptive strike. This was the first such occasion but it probably will not be the last.

We in the United States are now in the position of having provided the planes that made the attack on a nuclear reactor that was constructed with French help and guidance. It is a first and an unpleasant one, both on the score of the French involvement and of the Israeli attack conducted entirely on their own initiative. Reportedly, the destroyed reactor had been duly inspected by the International Atomic Energy Agency. The Israelis were apparently unimpressed, claiming there was provision at the Iraqi site for separation of plutonium from the reactor material.

Most of the 50,000 nuclear weapons are now in the hands of the United States and the Soviet Union. Both Britain and France have sizable and effective but much smaller stocks. The Chinese have nuclear weapons and delivery vehicles of publicly unknown number and quality, but probably small compared to the United States and the Soviet Union. India has exploded a bomb and may have some others. Several nations which have not exploded bombs probably have modest stocks of weapons. In recent years more nations have joined this latter group, and it seems likely that the number of nations capable of producing nuclear weapons will increase in this decade. If this happens and if nuclear material-especially plutonium-for bombs is easily available, some of the technically strong nations that have disavowed nuclear weapons may change their policies. Unless some move is made soon to reduce stocks of nuclear weapons, the probability of their use, whether by accident or design, will be greatly increased.

In view of this ominous situation it is imperative to find some new ways of rapprochement. Reduction of stocks directly by the United States and the Soviet Union seems to be the only way to get started. Moves through the United Nations have been made for 35 years, yet stockpiles and proliferation are on the rise. If the United States and the Soviet Union would actually start some reduction, it could have major effect:

- Other nations might be persuaded to join,

- Collaboration, even on a small scale as a start, might greatly decrease the probability that the United States and the Soviet Union would find themselves in confrontation with each other as a result of third-party action.

On the occasion of receiving the Albert Einstein Peace Prize, George Kennan gave a moving address on the dangers of the escalating nuclear weapons situation. He spoke strongly, even prior to the Isracli attack on the Iraqi nuclear reactor, about the seriousness of the present situation. Kennan made the suggestion that

"the President ... . after due consultation with the Congress ... propose to the Soviet government an immediate across-the-board reduc-

(continued on page 4) 


\section{Reduction of weapons}

(continued from page 1)

tion by 50 percent of the nuclear arsenals now being maintained by the two superpowers-a reduction affecting in equal measure all forms of the weapon, strategic, mediumrange, and tactical as well as all means of their delivery-all this to be implemented at once and without further wrangling among the experts, and to be subject to such national means of verification as now lie at the disposal of the two powers."

Kennan proposed further reductions at a later time but made no mention of conditions for participation of other powers. No reference was made to the United Nations.

This is a powerful proposal. Somewhat similar ones have been made in desperation by workers in this field before, but with no hope that anyone would take them seriously. But Kennan is very serious. This appeal goes further than one that he made several years ago. He puts the proposal entirely on a two-nation basis and emphasizes the need for rapid movement.

One reason that such a dramatic suggestion might now be acceptable as an objective to the United States and the Soviet Union is that the nuclear stockpiles and delivery systems are so large that a reduction to one-half would still leave each superpower with an overwhelming force. Although the 50 percent reduction would not solve the nuclear disarmament problem it would be a start. Kennan suggests that after this initial move there should be a further reduction by two-thirds and, presumably, others to come.

Kennan's proposal for a 50 percent reduction initially is one which would shock both U.S. and Soviet military personnel, who would probably op- pose it vigorously. But such a drastic reduction may not be necessary to get the process started.

Instead of making a 50 percent reduction in a single move, it would perhaps be more effective to do it in several steps. The first could be entirely bilateral, involving only the United States and the Soviet Union, and for a more modest 5 or 10 percent. For such a decrease it would matter less just which weapons on each side were reduced, and therefore it should be easier to come to an agreement. The objective would be to get the reduction started by both nations.

It would be highly desirable to have other nations with nuclear armaments participating in an agreement for weapons reduction to some reasonable level. But making this a provision for starting has serious disadvantages and leads to interminable delays. Provision should be made, however, to welcome other nuclear powers as adherents. Sufficiently complete nuclear disarmament cannot be achieved without participation of all nuclear powers, but adherence of other nations should not be a condition for initiating the reduction.

The Kennan proposal seems to give inadequate encouragement or rationale for other nuclear weapons states to join the superpowers. Perhaps to achieve this a further and stronger step is necessary. One proposal is for the United States and the Soviet Union to agree that, in addition to their own reductions, they would immediately consult with each other in any situation in which nuclear weapons might be used or newly developed by others. They would then report the reasons for their concern to the International Atomic Energy Agency. In this Agency both powers have a record of participation and reasonable agreement. The degree to which the United States and the Soviet Union would act together would not be specified in advance.
Along with a joint agreement to reduce their nuclear weapons by half, in stages, there would be a basis for continued consultation and joint action. The history of the past 20 years seems to make it reasonably unlikely that either the United States or the Soviet Union would, independently and without nuclear action involving other nations, make a frontal attack on the other. The prospect of devastating retaliation in either direction so far has been a strong deterrent. It is therefore very much in the interest of both nations to minimize the chance that other nations would start a conflagration that might involve the United States and the Soviet Union on opposite sides.

It is noteworthy that the Soviet Union has, so far as is known public$1 y$, been meticulous in the handling of nuclear weapons by other members of the Soviet bloc and in the processing of spent reactor fuel which might put other members in possession of weapons material. Compared to the Soviet bloc the rest of the world is chaotic in regard to control. Britain and France and their nuclear reactor partners, as well as Japan, turned down the U.S. proposal not to reprocess spent fuel until arrangements for international control or some arrangement for joint processing could be set up. Those nations are going ahead with plans to separate plutonium from spent reactor fuel, and to use it. These recent happenings make it clear that the place to achieve some international agreement is directly with the Soviet Union.

In the past the Soviet Union has never taken any real action that would make it seem likely that they would look with favor either on Kennan's proposal or on that proposed here. Moscow agreed to SALT 1 and to SALT II and Washington has agreed to SALT I but has not yet ratified SALT II although the Soviet Union has been pressing for agreement. SALT II does 
not go very far and our reticence to sign the treaty has been used effectively by the Soviets to put us in the position of not going along with even a relatively weak control agreement.

Let us now propose specific cuts of 5 percent in current nuclear weapon systems-and start to make them. This would not weaken our deterrent capability appreciably. Let us then propose to the Soviet Union that they make similar cuts in their nuclear weapon systems. After this process is well started, the United States and the Soviet Union should begin negotiations as to how further cuts could be agreed upon and made up to Kennan's 50 percent as an initial goal. Let us also propose that the agenda include an exchange of views on nuclear weapons in the hands of other nations, and that there should be an agreement to consult together immediately if either nation finds evidence of preparation for nuclear aggression, or evidence of nuclear weapon production, in hitherto unknown programs. And further, after the United States and the Soviet Union have each made their initial step of 5 percent reduction, both should welcome the adherence and participation of other nuclear powers in the weapons reduction program.

Many in the United States would feel strongly that such a step would be wildly dangerous. But if the full 50 percent reduction proposed by Kennan were taken in stages and in a way to be mutually verified, the danger would decrease rather than increase. If real reduction in nuclear armaments were achieved by an agreed procedure, the tension between the superpowers could only decrease. Furthermore, real pressure could be brought on other nuclear powers and on potential nuclear powers to pursue a similar if not identical policy.

The principal difference in this procedure compared to past suggestions is that some action would be taken early, not delayed until after discussion by a large number of nations with quite different nuclear capabilities.

Many in the United States would undoubtedly feel that it is a waste of time, given Russian and Soviet history, to pursue a course that would depend upon their reduction of armaments. There are at least two points against this view: one is that recent Soviet military steps relating to nuclear armament do not indicate that they see an effective means of nuclear defense. This is a new situation. It is true that they have greatly strengthened their position relative to the West in the past few years and this is a policy we cannot overlook for long. But they also are vulnerable. The other point is that, in the Eastern bloc, they have kept nuclear weapons control and manufacture to themselves. When it became clear that they could not control Chinese nuclear exploitation they immediately withdrew their support. China is a source of greater danger for them than for us.

If we act together with the Soviets in nuclear weapons reduction and control it would greatly complicate our evolving relations with China. The Chinese have shown no interest in arms control largely because of their fear of Russia. This fear was very likely a major motivation toward more friendly relations with the United States. If the United States and the Soviet Union agreed not only to reduce nuclear weapons but to consult and possibly act together with respect to international nuclear problems, the strongest objections would probably come from the Chinese. But, while China's nuclear forces are growing, they are still very small compared to those of the United States and the Soviet Union. Recognizing this, China might be pleased to see nuclear weapons diminish in number, especially those in Soviet hands. Thus, China might be prepared to consider a freeze at present levels, leading to reduction after significant United States and Soviet reductions were made. Having an "adequate" nuclear capability in a world where stronger nuclear powers are pressing for reduction by all is not an enviable position.

It seems best, considering the record of the past 35 years, to proceed directly with a proposal to the Soviet Union. This could be couched in terms of a statement of initial reductions to be made by the United States and a proposal that the Soviet Union do likewise. Most important should be a proposal for discussions aimed at further reductions and, after this, the enlistment of other nuclear powers to follow suit.

There is probably not much chance that the present pattern of negotiations established in SALT I and II will get anywhere. Something different is needed. Recent decisions in Europe to go ahead with plutonium production and separation are probably in part due to lack of confidence in the United States. We need a new policy that puts us once again in the lead in our advocacy of nuclear weapons reduction and international control.

Robert F. Bacher is professor of physics emeritus at the California Institute of Technology in Pasadena (91109). Bacher was a member of the faculty at Cornell University from 1935 to 1949 , and worked

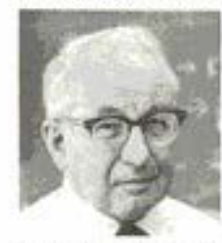
at Los Alamos from 1943 to 1945 . He served as a member of the first Atomic Energy Commission (1946-1949). Bacher

joined the faculty at Caltech in 1949 , and was provost from 1962 to 1970 . He was a member of the President's Science Advisory Committee from 1957 to 1960 , and is a founding sponsor of the Bulletin. 